\title{
Phyllodes Tumors: What is the Best Therapeutic Option?
}

\author{
Camylla de Souza Landal \\ Academic of University of Vale do Itajaí, Brazil \\ *Corresponding author: Camyllade Souza Landal, Academic of University of Vale do Itajaí, Itajaí, Brazil
}

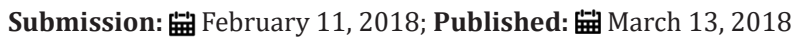

\begin{abstract}
Phyllodes tumors of the breast are a rare tumor, accounting for only $1 \%$ of breast tumors. It has a fast growth, resembling fibro adenoma in its shape. It is classified as benign, borderline and malignant. It has a high relapse rate, with $27 \%$ in malignant tumors. And globally they metastasize in about $4 \%$ of the cases, being usually hematologically. From the moment of the diagnosis made by the anatomopathological study, the best therapeutic option consists of surgical resection with free safety margins, and it can be extended to mastectomy without axillary dissection in the case of malignancy or tumors with a larger diameter. The use of adjuvant therapies still remains questioned.
\end{abstract}

Keywords: Phyllodes tumors; Breast neoplasms; Therapeutics

\section{Introduction}

Being reported in 1838 by Johannes Muller, phyllodes tumors of the breast are fibro epithelial neoplasms, similar in form to fibro adenoma [1-3]. Since 2003 it has been classified by the World Health Organization in: benign, borderlines and malignant. According to the degree of a typia, mitotic activity, tumor margins characteristics and the presence of stromal development [4]. It is a rare tumor, with only $1 \%$ of breast tumors, $2 \%$ to $3 \%$ of fibro epithelial tumors and the most frequent sarcoma of the breast. It has a higher incidence between 35-55years old [4].

They are tumors that start as palpable small but rapidly growing nodules. Its diagnosis must be made by anatomopathological examination, through histological findings-fibroepithelial lesion, stromal proliferation, hypercellularity and elongated and tortuous ductal components, with leaf-type endoluminal stroma projections [5]. The best therapeutic option consists of surgical management due to high relapse, with a recurrent rate of $27 \%$ in malignant tumors, $25 \%$ in borderlines and $17 \%$ in malignant tumors. The determining factors for relapse are related to the histological type, stromal atypia, stromal hypercellularity, and spreading margin [5].

The overall metastatic indexes of phyllodes tumors are 4\%, and in the malignant tumors an isolated index of $25 \%$. The main pathway of metastasis is hematogenous, and lymph node involvement is not common. When dissemination occurs, the most common locations are: lung, followed by soft tissue, bone and pleura [5]. The increased risk of metastasis occurs according to the time of diagnosis, tumor size and presence of necrosis [1]. The survival rate for malignant tumors is reported as about 60 to $80 \%$ over 5years [6]. The possible differential diagnoses for malignant phyllode tumor are: giant fibroadenoma, mastitis, breast abscess, complicated breast cyst, inflammatory carcinoma and breast trauma [5].

\section{Therapeutic Options}

Malignant phyllodes tumors have a high recurrence rate, reaching $27 \%$ in some studies and a metastatic rate of $25 \%$, in addition to the psychological and aesthetic morbidity in which these patients undergo [5]. Therefore, in a series of literature review, all studies are categorical in pointing to surgical treatment as the best therapeutic option, but there are still differences regarding local resection with negative margins or simple mastectomy - without lymph node emptying by hematologic pattern of metastasis - and also the association with radiotherapy, chemo or hormone therapy.

\section{Surgical resection}

Surgical resection is the therapeutic choice and malignant phyllodes tumors or tumors with benign characteristics greater than $5 \mathrm{~cm}$ are recommended for extensive local excitation or mastectomy without axillary emptying. Tumorectomy with margins of 1 to $2 \mathrm{~cm}$ is recommended only for small $(<5 \mathrm{~cm})$ and benign tumors [6-9].

\section{Adjuvant treatment}

Although studies on the use of adjuvant therapies are found, nothing is conclusive, insofar as most studies have a small sample ' $n$ ' or segment below 10years or still show low statistical significance when compared to control groups [8-10]. It is necessary to 
individualize the use or not of adjuvant therapy according to tumor histology, mitotic activity, stromal cell hyperplasia and degree of atypia $[1,11]$. As an example of the possibility of intervention with adjuvant therapy, there are tumors with incomplete resection and tumors with a diameter $>5 \mathrm{~cm}$ and with histological evidence of excessive stromal growth because they have a higher metastatic potential [12,3] (Table 1,2).

\section{Conclusion}

Since phyllode tumor of the breast is a relapsed neoplasm of recurrence and a high chance of malignancy in borderline cases, the first-line treatment option for small tumors $(<5 \mathrm{~cm})$ and benign tumors is surgical resection with margins of 1 to $2 \mathrm{~cm}$. Malignant tumors or larger than $5 \mathrm{~cm}$ in diameter require mastectomy without axillar emptying. The use of adjuvant therapies is still discussed. Until there is a large study confirming and affirming its use positively, it is recommended to individualize each case.

\section{References}

1. Zhou ZR, Wang CC, Yang ZZ, Yu XL, Guo XM (2016) Phyllodes tumors of the breast: diagnosis, treatment and prognostic factors related to recurrence. J Thorac Dis 8(11): 3361-3368.

2. Muller J (1838) Ueber den feinen bau unddie furmen der krankhaften geschwulste. Berlin: G Reimer 1: 54-57.

3. Warner WA, Sookdeo VD, Fortuné M, Akhilesh M, Venkata CRA, et al. (2017) Clinicopathology and treatment of a giant malignant phyllodes tumor of the breast: A case report and literature review. Int J Surg Case Rep 41: 259-264.
4. Rodrigues GCR, França MK, Valença SC, Pereira BP, Neto JEVB, et al. (2014) Bilateral malignant phyllodes tumor of breast: a case report. Rev Bras Mastologia 24(2): 57-59.

5. Moreira KC, Sales WT, Santos EK (2012) Malignant phyllodes tumor with pleomorphic liposarcomatous stroma in the breast. Rev Bras Mastologia 22(2): 66-69.

6. Pereirae Silva KF, Vendrami CD, Castilho TJ, Silva LV, Ribeiro R, et al. (2013) Phyllodes breast tumor: case series and review of literature. Rev Bras Mastologia 22(2): 42-45.

7. Issara K, Houjami M, Sahraoui S, Bouchbika Z, Benchakroun N, et al. (2016) Tumeur phyllode chez une jeune adolescente de 12 ans: à proposdun cas et revue de la literature. Pan Afr Med J 25: 20.

8. Khosravi Shahi P (2011) Management of non metastatic phylloides tumors of the breast: Review of the literature. Surg Oncol 20(4): e143-e148.

9. Spitaleri G, Toesca A, Botteri E, Bottiglieri L, Rotmensz N, et al. (2013) Breast phyllodes tumor: A review of literature and a single center retrospective series analysis. Crit Rev Oncol Hematol 88(2): 427-436.

10. Kim YJ, Kim K (2017) Radiation therapy for malignant phyllodes tumor of the breast: An analysis of SEER data. The Breast 32: 26-32.

11. Barth RJ, Wells WA, Mitchell SE, Cole BF (2009) A prospective, multiinstitutional study of adjuvant radiotherapy after resection of malignant phyllodes tumors. Ann Surg Oncol 16(8): 2288-2294.

12. Chaney AW, Pollack A, Mcneese M, Zagars GK, Pisters PWT, et al. (2000) Primary treatment of cystosarcoma phyllodes of the breast. Cancer 89(7): 1502-1511.
Creative Commons Attribution 4.0 International License

For possible submissions Click Here

\section{Submit Article}

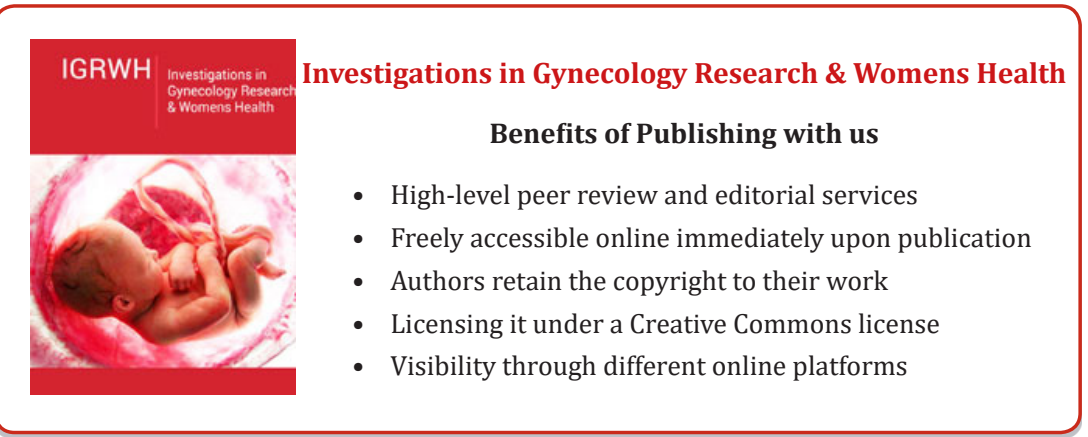

